\title{
Lead impedance, pacing threshold and percentage of ventricular pacing according to the lead age - a cross-sectional study on patients during follow-up
}

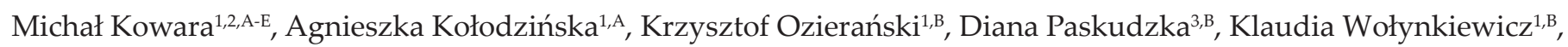
Edyta Jakubik ${ }^{1, \mathrm{~B}}$, Maciej Kubik ${ }^{2, \mathrm{D}}$, Karolina Rybak ${ }^{2, \mathrm{D}}$, Marcin Grabowski ${ }^{1, \mathrm{E}-\mathrm{F}}$, Grzegorz Opolski1,,F

A - Research concept and design, B - Collection and/or assembly of data, C - Data analysis and interpretation,

D - Writing the article, E - Critical revision of the article, F - Final approval of article

$11^{\text {st }}$ Department of Cardiology, Medical University of Warsaw

2 Chair and Department of Experimental and Clinical Physiology, Medical University of Warsaw

3 Medical University of Warsaw

Address for correspondence:

Dr Michał Kowara, $1^{\text {st }}$ Department of Cardiology, Medical University of Warsaw

Chair and Department of Experimental and Clinical Physiology, Medical University of Warsaw

email: michal.kowara@wum.edu.pl

Prof. Agnieszka Kołodzińska, $1^{\text {st }}$ Department of Cardiology, Medical University of Warsaw amail: aa.kolodzinska@wp.pl

Dr Krzysztof Ozierański, $1^{\text {st }}$ Department of Cardiology, Medical University of Warsaw email: krzysztof.ozieranski@gmail.com

Dr Diana Paskudzka, Medical University of Warsaw

email: paskudzkadiana@gmail.com

Dr Klaudia Wołynkiewicz, $1^{\text {st }}$ Department of Cardiology, Medical University of Warsaw email: klaudiawolynkiewicz@gmail.com

Dr Edyta Jakubik, $1^{\text {st }}$ Department of Cardiology, Medical University of Warsaw email: edytajakubik@gmail.com

Maciej Kubik, Chair and Department of Experimental and Clinical Physiology, Medical University of Warsaw email: maciej.kubik1998@gmail.com

Karolina Rybak, Chair and Department of Experimental and Clinical Physiology, Medical University of Warsaw email: karolinamariarybak@gmail.com

Prof. Marcin Grabowski, $1^{\text {st }}$ Department of Cardiology, Medical University of Warsaw email: marcin.grabowski@wum.edu.pl

Prof. Grzegorz Opolski, $1^{\text {st }}$ Department of Cardiology, Medical University of Warsaw email: grzegorz.opolski@wum.edu.pl

Received: 2020-09-30

Revised:

Accepted: 2020-09-30

Final review:

DOI:

Key words:

ventricular lead, impedance, pacemaker, follow-up, pacing threshold

\section{Abstract}

\section{Background}

Patients with permanent pacemakers should be followed up regularly and parameters recorded during the follow-up visits might have potential for further diagnostic studies.

\section{Material and methods}

A pilot cross-sectional study on 127 consecutive patients who underwent pacemaker follow-up was performed.

\section{Results}

The study revealed that patients with older ventricular leads (more than 10 years) have higher lead impedance in comparison with patients with newer ventricular leads (less than 10 years) $-512 \Omega$ vs $461 \Omega$ (median values), with no differences in pacing thresholds, percentage of ventricular pacing, presence of ventricular high rate episodes or status of absolute pacemaker dependency.

\section{Conclusions}

This study demonstrates that parameters obtained from a regular pacemaker check-up differ according to variables such as lead age, which opens a new field for studies investigating other variables (e.g. disease biomarkers) in correlation with parameters from the pacemaker check-up. 


\section{Introduction}

The principal indications for pacemaker implantation are sick sinus syndrome and advanced atrioventricular block, as has been pointed out in the European Society of Cardiology Guidelines (2013) ${ }^{[1]}$. According to the 11th world survey of cardiac pacing, in 2009 alone there were 737840 new implantations and 264824 replacements of pacemakers in 61 countries (including the USA) ${ }^{[2]}$. After the implantation patients should be followed up regularly and pacemakers must be checked at least once a year ${ }^{[3]}$. During the check-up visit the following parameters are evaluated - battery longevity, pacing thresholds, $\mathrm{P}$ and R-wave sensing, lead impedance values, percentage of paced/sensed beats, status of pacemaker dependency and arrythmia episodes (atrial - AHRE and ventricular - VHR). Regular follow-up allows for arrangement of elective device replacement according to the elective replacement indicator and quick detection of pacemaker malfunction. Moreover, arrythmia detection enables therapy adjustments if necessary. New algorithms in ICD/CRT-D patients such as CoreVue and Optivol are valuable tools for early detection of heart failure exacerbation, which gives an opportunity for pharmacotherapy modification and avoidance of urgent hospitalization ${ }^{[4,5]}$. However, it is unknown how pacemaker control can be useful in the detection of diseases other than arrythmias. Prior to the investigation of this issue it is necessary to study the differences between parameters checked during follow-up pacemaker control. Because pacing leads are a "weak point" of permanent pacing therapy and older leads are more susceptible to abrasions, we examined differences between patients with older ( $>10$ years) and newer ( $<10$ years) ventricular leads in our pilot cross-sectional study ${ }^{[6,7]}$.

\section{Materials and methods}

\section{Study population}

In our pilot cross-sectional study on the data from one month we enrolled 127 consecutive patients with an active ventricular lead (both single-chamber and dual-chamber pacing in VVI, VDD or DDD mode) checked during the follow-up visits in the Center of Control and Telemonitoring of Implantable Cardiac Devices of the $1^{\text {st }}$ Department of Cardiology, Medical University of Warsaw.

Patients with only atrial or epicardial leads were excluded as well as patients who required urgent hospitalization and patients with suspected ventricular lead damage.

\section{Pacemaker check-up procedures}

All patients had their pacemaker checked according to the manufacturers' guidelines, on certified testing devices provided by Biotronik, Medtronic and St. Jude Medical (Abbot Vascular). The following data were recorded: current lead impedance (bipolar configuration), current pacing threshold, percentage of ventricular pacing, pacemaker dependency and presence of ventricular high rate episodes (VHR). Pacing thresholds were assessed manually - the minimal amplitude capable of evoking the effective pacing was considered as the value of the pacing threshold. The information about pacemaker dependency was collected from the previous patient visit. In case of doubt the tests for pacemaker dependency with back-up ventricular pacing of 30/min were conducted.

\section{Data collection and statistical analysis}

Statistical analysis (Shapiro-Wilk normality test, Mann-Whitney U-test, chi-square test) was performed using STATISTICA 13 (StatSoft Inc.)

\section{Results}

\section{Baseline characteristics}

Patients were divided according to the lead age - older leads $(\mathrm{O})$, more than 10 years since the implantation and newer leads $(\mathrm{N})$, less than 10 years since the implantation. There were 69 subjects with older leads (54.3\%) and 58 (45.7\%) with newer leads. Patients with newer leads were younger. Ventricular leads older than 10 years were mainly from Biotronik, whereas leads younger than 10 years were mainly from Medtronic. The differences in baseline characteristics of patients from the two groups are presented in Table 1.

\begin{tabular}{|l|l|l|l|}
\hline & Newer lead (N) & Older lead (0) & P significance\# \\
\hline Women, $\mathbf{n}(\%)$ & $36(62.1 \%)$ & $33(47.8 \%)$ & 0.1 (NS) \\
\hline Age* & $85[74-88]$ & $79[69-87]$ & $0.03 \#$ \\
\hline $\begin{array}{l}\text { Medtronic } \\
\text { ventricular } \\
\text { lead, } \mathbf{n}(\%)\end{array}$ & $33(56.9 \%)$ & $20(29 \%)$ & $0.0015 \#$ \\
\hline $\begin{array}{l}\text { Biotronik } \\
\text { ventricular } \\
\text { lead, } \mathbf{n}(\%)\end{array}$ & $17(29.3 \%)$ & $43(62.3 \%)$ & $0.002 \#$ \\
\hline $\begin{array}{l}\text { St. Jude } \\
\text { Medical } \\
\text { ventricular } \\
\text { lead, } \mathbf{n}(\%)\end{array}$ & $8(13.8 \%)$ & $6(8.7 \%)$ & 0.36 (NS) \\
\hline
\end{tabular}

Pacing threshold, percentage of ventricular pacing and lead impendence comparison

It was found that subjects with older leads $(\mathrm{O})$ had significantly higher lead impedance compared to subjects with newer leads (median values $512 \Omega$ vs $461 \Omega$, p = 0.03).

No significant differences in the percentage of ventricular pacing and current ventricular lead threshold were found (Figure 1).

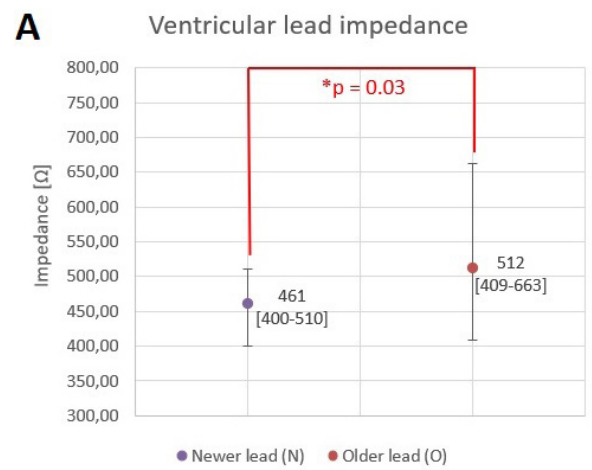



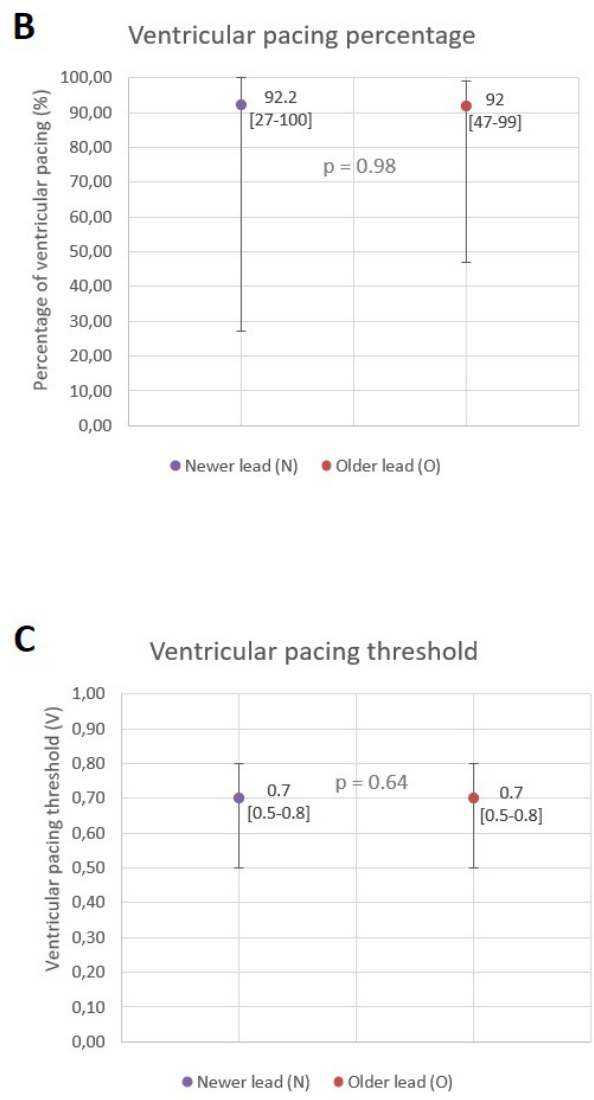

\section{Ventricular high rate episodes and pacemaker dependence comparison}

The study revealed no significant difference in VHR between patients with older and newer leads. Also, the percentage of absolute pacemaker dependence (i.e. no patient's own heart rhythm when back-up stimulation VVI 30/min is applied) did not differ between the groups (Table 2).

\begin{tabular}{|l|l|l|l|}
\hline & Newer lead (N) & Older lead (0) & P significance\# \\
\hline $\begin{array}{l}\text { Number of } \\
\text { patients with } \\
\text { VHR, } \mathbf{n}(\%)\end{array}$ & $10(17.2 \%)$ & $17(23.2 \%)$ & 0.4 (NS) \\
\hline $\begin{array}{l}\text { Number of } \\
\text { patients with } \\
\text { absolute } \\
\text { pacemaker } \\
\text { dependence*, } \\
\mathbf{n}(\%)\end{array}$ & $20(34.5 \%)$ & $24(34.8 \%)$ & 0.97 (NS) \\
\hline
\end{tabular}

\section{Discussion}

The results of our cross-sectional study showed that patients with a permanent pacemaker with older ventricular leads present had higher lead impendence in comparison with patients with newer ventricular leads. An old study conducted in the 1980s showed that this parameter changes during the follow-up and both ventricular and atrial lead impedance decreases after the implantation within a period of 13 months ${ }^{[8]}$. From a clinical perspective, a sudden and prominent increase or decrease in lead impedance might indicate lead damage or malfunction ${ }^{[9]}$. Nevertheless, there were some studies that aimed to correlate such parameters as the aforementioned lead impedance or pacing threshold with cardiovascular diseases. For instance, Stambler and colleagues found a correlation between ventricular lead impedance decrease and both left ventricle ejection fraction (LVEF) decrease and heart failure symptoms exacerbation (according to the New York Heart Association class) ${ }^{[10]}$. This relation however was only observed when the ventricular lead was placed in the right ventricle (RV) apex, not in the RV outflow tract. Another study performed on 130 patients with a pacemaker or implantable cardioverter-defibrillator (ICD) revealed no associations between pacing parameters (lead impedance and pacing threshold) and distribution of LVEF or coronary artery disease, although the mean lead impedance was lower and mean pacing threshold was higher in the ICD patients than in pacemaker patients ${ }^{[11]}$. Pacing parameters might also be modified by proliferative scarring within the myocardium - the study by Vurgun et al. showed that patients with proliferative scars in the right ventricle had a significantly higher pacing threshold compared with the control group matched by sex, age and lead type ${ }^{[12]}$.

Our pilot cross-sectional study showed that the parameters obtained from a regular pacemaker check-up differ according to variables such as lead age. This finding opens a new area of research on hypothetical correlations between certain biomarkers of different diseases and pacemaker parameters. Moreover, the study on certain types of leads might bring more information about their long-term features, especially in reference to some clinical conditions. However, our study has many limitations - a small sample size, lack of differentiation according to lead types, series and position on X-ray. Therefore it should be considered only as a pilot study, which opens a new field for further investigations.

\section{Acknowledgements}

We would like to acknowledge our professional technician, Mr Arkadiusz Brodowski, for irreplaceable technical support.

\section{References}

1. Brignole, M., A. Auricchio, G. Baron-Esquivias, et al., 2013 ESC Guidelines on cardiac pacing and cardiac resynchronization therapy: the Task Force on cardiac pacing and resynchronization therapy of the European Society of Cardiology (ESC). Developed in collaboration with the European Heart Rhythm Association (EHRA). Eur Heart J, 2013. 34(29): p. 2281-329.

2. Mond, H.G. and A. Proclemer, The 11th world survey of cardiac pacing and implantable cardioverter-defibrillators: calendar year 2009--a World Society of Arrhythmia's project. Pacing Clin Electrophysiol, 2011. 34(8): p. 1013-27. 
3. Roberts, P.R., Follow up and optimisation of cardiac pacing. Heart, 2005. 91(9): p. 1229-34.

4. Boehmer, J.P., R. Hariharan, F.G. Devecchi, et al., A Multisensor Algorithm Predicts Heart Failure Events in Patients With Implanted Devices: Results From the MultiSENSE Study. JACC Heart Fail, 2017. 5(3): p. 216-225.

5. Palfy, J.A., J. Benezet-Mazuecos, J. Martinez Milla, et al., CorVue algorithm efficacy to predict heart failure in real life: Unnecessary and potentially misleading information? Pacing Clin Electrophysiol, 2018.

6. Kutarski, A., B. Malecka, A. Kolodzinska, et al., Mutual abrasion of endocardial leads: analysis of explanted leads. Pacing Clin Electrophysiol, 2013.36(12): p. 1503-11.

7. de Voogt, W.G., Pacemaker leads: performance and progress. Am J Cardiol, 1999. 83(5B): p. 187D-191D.

8. Platia, E.V. and J.A. Brinker, Time course of transvenous pacemaker stimulation impedance, capture threshold, and electrogram amplitude. Pacing Clin Electrophysiol, 1986. 9(5): p. 620-5.

9. Senoner, T., F. Barbieri, G. Semmler, et al., Longterm performance of an atrial lead capable of accelerometer based detection of cardiac contractility in patients receiving cardiac resynchronisation therapy. PLoS One, 2019. 14(9): p. e0222269.

10. Stambler, B.S., K.A. Ellenbogen, Z. Liu, et al., Serial changes in right ventricular apical pacing lead impedance predict changes in left ventricular ejection fraction and functional class in heart failure patients. Pacing Clin Electrophysiol, 2005. 28 Suppl 1: p. S50-3.

11. Ekinci, S., M. Yesil, S. Bayata, et al., An observational study of the effect of coronary artery disease severity on acute pacing threshold and lead impedance in patients with permanent pacemaker. Anadolu Kardiyol Derg, 2012. 12(3): p. 208-13.

12. Vurgun, V.K., E. Baskovski, H. Goksuluk, et al., Evaluation of right ventricular pacing parameters in patients with proliferative scar. J Interv Card Electrophysiol, 2018. 53(2): p. 249-254. 